\title{
Parâmetros hematológicos e bioquímicos de bezerros neonatos da raça Holandesa tratados com ferro suplementar ${ }^{1}$
}

\begin{abstract}
Camila Franciosi² ${ }^{2}$ Thaís G. Rocha ${ }^{2 *}$ e José J. Fagliari²
ABSTRACT.- Franciosi C., Rocha T.G. \& Fagliari J.J. 2018. [Hematological and biochemical parameters of neonatal Holstein calves supplemented with iron.] Parâmetros hematológicos e bioquímicos de bezerros neonatos da raça Holandesa tratados com ferro suplementar. Pesquisa Veterinária Brasileira 38(2):234-243. Programa de Pós-Graduação em Medicina Veterinária, Faculdade de Ciências Agrárias e Veterinárias, Universidade Estadual Paulista "Júlio de Mesquita Filho", Campus de Jaboticabal, Via de Acesso Prof. Paulo Donato Castellane s/n, Jaboticabal, SP 14884-900, Brazil. E-mail: thaisgrocha@yahoo.com.br

Iron deficiency in newborn calves is associated with the development of anemia, which favors the development of other infirmities such as pneumonia and diarrhea. The present study evaluated the effect of iron supplementation on erythrogram, serum levels of iron, ceruloplasmin and tranferrin, as well as potential toxicity of the protocol used by means of evaluation of urea, creatinine and hepatic enzyme activities. 40 newborn Holstein calves were allocated into 5 experimental groups comprising 8 calves each, which were subjected to the following treatment protocols: intramuscular administration of $5 \mathrm{~mL}$ of sterile saline on the 5 th day of age (control group G1), intramuscular administration of $5 \mathrm{~mL}$ of $10 \%$ dextran iron in the following moments: on the 5th day of age (G2); on the 5th and in the 20th day of age (G3); on the 5th and 30th day of age (G4); on the 5th, 20th and 45th days of age (G5). Blood samples were taken until 8 hours after birth and with 5, 10, 20, 30, 60, and 90 days of age, and subjected to hemogram, evaluation of serum levels of iron, ceruloplasmin, transferrin, urea, creatinine, total and direct bilirrubin, and serum activities of aspartate aminotransferase (AST), alcaline phosphatase (ALP), and gamma-glutamyltransferase (GGT). Calves that received iron supplementation at any time presented less variation in the erythrocyte parameters, although calves in the control group did not develop anemia. Serum concentration of iron and acute phase protein ceruloplasmin and transferrin, which activities are related to iron metabolism, also increased, although not significantly. Serum levels of urea, creatinine, bilirubins and activities of AST, ALP, and GGT were not influenced by the administration protocols used in this experiment. The results of the experiment led to the conclusion that the supplementation with parenteral dextran iron in calves that receive diets other than exclusive milk does not bring sufficient advantages to be indicated, although more studies are necessary to evaluate the influence of iron supplementation on the outcome of infections in newborn calves, especially its influence on cost of treatment, time necessary for discharge and impact on its productive life.
\end{abstract}

INDEX TERMS: Anemia, newborn calves, ceruloplasmin, iron supplementation, clinics.

RESUMO.- A deficiência de ferro em bezerros neonatos está associada ao desenvolvimento de anemia, que favorece o aparecimento de outras enfermidades como pneumonia

\footnotetext{
${ }^{1}$ Recebido em 19 de abril de 2016. Aceito para publicação em 24 de novembro de 2016.

${ }^{2}$ Faculdade de Ciências Agrárias e Veterinárias (FCAV), Universidade Estadual Paulista "Júlio de Mesquita Filho" (Unesp), Campus de Jaboticabal, Via de Acesso Prof. Paulo Donato Castellane s/n, Jaboticabal, SP 14884900, Brasil. *Autor para correspondência: thaisgrocha@yahoo.com.br
}

e diarreia. Avaliou-se o efeito da suplementação de ferro sobre o eritrograma, teores séricos de ferro, ceruloplasmina e transferrina, bem como o potencial para toxicidade do protocolo utilizado por meio da avaliação dos teores de ureia, creatinina e enzimas hepáticas. Para tal avaliação foram utilizados 40 bezerros neonatos da raça Holandesa, alocados em cinco grupos experimentais com oito animais em cada grupo, que foram submetidos aos seguintes protocolos: administração intramuscular de $5 \mathrm{~mL}$ de solução fisiológica 
estéril no 5o dia de idade (grupo controle G1), e administração intramuscular de $5 \mathrm{~mL}$ de ferro dextrano $10 \%$ nos seguintes momentos: no $5^{\circ}$ dia de idade (G2); no $5^{\circ}$ e no $20^{\circ}$ dias de idade (G3); no $5^{\circ}$ e no $30^{\circ}$ dias de idade (G4) e no $5^{\circ}, 20^{\circ}$ e $45^{\circ}$ dias de idade (G5). Foram coletadas amostras de sangue até 8 horas após o nascimento e aos 5, 10, 20, 30, 60 e 90 dias de idade para realização do eritrograma, avaliação dos teores séricos de ferro, ceruloplasmina, transferrina, ureia, creatinina, bilirrubina total e direta, e das atividades das enzimas aspartato aminotransferase (AST), fosfatase alcalina (ALP) e gamaglutamiltransferase (GGT). Os animais que receberam ferro suplementar apresentaram menor oscilação nos parâmetros eritrocitários, embora os animais do grupo controle não tenham desenvolvido anemia. Notou-se também aumento, embora não significativo, nos teores séricos de ferro e das proteínas de fase aguda ceruloplasmina e transferrina, cuja atividade está relacionada ao metabolismo desse mineral. Os teores séricos de ureia, creatinina, bilirrubina total e direta e as atividades das enzimas GGT, AST e ALP não foram influenciados pelos protocolos de administração de ferro suplementar. Os protocolos de tratamento empregados não ocasionaram hepatoxidade ou nefrotoxidade aos animais. Concluiu-se que a suplementação com ferro dextrano por via parenteral em bezerros que recebem outras dietas que não apenas leite não traz benefícios que justifiquem sua indicação, embora sejam necessários mais estudos que avaliem a influência da suplementação com ferro sobre o tempo necessário para a recuperação, custos com o tratamento e impacto sobre a vida produtiva dos animais na idade adulta.

TERMOS DE INDEXAÇÃO: Anemia, bezerros neonatos, ceruloplasmina, suplementação com ferro, clínica.

\section{INTRODUÇÃO}

A ocorrência de anemia interfere na taxa de crescimento dos animais, bem como influencia a ocorrência de enfermidades como pneumonia e diarreia neonatal (Ramin et al. 2012). A principal reserva de ferro no organismo de bezerros encontra-se no tecido hepático, e, em geral, essa reserva é suficiente para evitar a ocorrência de anemia grave se os bezerros receberem volumoso nas primeiras semanas de vida. Dessa forma, a ocorrência de anemia, em especial por deficiência de ferro, acomete com maior frequência bezerros que recebem dietas exclusivas a base de leite por várias semanas, podendo afetar as taxas de crescimento e a conversão alimentar desses animais (NRC 2001). Tal deficiência decorre da baixa concentração desse mineral no leite, crescimento pós-natal rápido dos animais e reserva escassa desse mineral no organismo (Moosavian et al. 2010).

Algumas pesquisas mostraram decréscimo abrupto no teor de ferro do colostro logo nas primeiras horas após o parto, bem como diminuição significativa na concentração sérica de ferro, contagem de hemácias e teor de hemoglobina em bezerros neonatos no decorrer das primeiras semanas de vida, que pode resultar em anemia (Fagliari et al. 1998, Rizzoli et al. 2006), no entanto, a ocorrência de anemia também pode estar relacionada a outros fatores nutricionais, tais como a falta de acesso dos bezerros a forragem nas primeiras semanas de vida, ou a deficiência de minerais como cobre, selênio, zinco e cobalto (Ramin et al. 2012).
Gygax et al. (1993) avaliaram a suplementação oral de ferro por meio do fornecimento de substituto do leite que continha 10 ou $50 \mathrm{mg} / \mathrm{kg}$ de ferro a bezerros, e relataram que a suplementação com $10 \mathrm{mg} / \mathrm{kg}$ foi ineficiente, ocasionando anemia, menor teor sérico de ferro, menor ganho de peso e maior incidência de infecções, em especial pneumonia. Também foi constatado que o número de neutrófilos com capacidade fagocítica, teor sérico de IgG e produção de linfócitos B pelos linfonodos foram reduzidos nos bezerros suplementados com essa dose.

Heidarpour Bami et al. (2008) relataram que a administração parenteral de ferro e/ou cobre influenciou parâmetros hematológicos tais como volume globular, bem como o ganho de peso e a incidência de enfermidades em bezerros neonatos com aptidão leiteira, sendo que a suplementação apenas com ferro aumentou o ganho de peso desses animais no decorrer do primeiro mês de vida.

Mohri et al. (2004), suplementaram 20 bezerros com $150 \mathrm{mg} /$ dia de sulfato ferroso por 28 dias a partir do nascimento, obtendo valores significativamente maiores no volume globular e teor sérico de hemoglobina. Moosavian et al. (2010) conduziram um estudo com suplementação de ferro injetável e vitamina A em 40 bezerros da raça Holandesa e verificaram aumento significativo nos parâmetros eritrocitários, tanto nos animais que receberam apenas ferro suplementar, como também nos que receberam suplementação concomitante de ferro e vitamina A.

O objetivo do presente estudo foi avaliar a influência do tratamento com ferro suplementar sobre o eritrograma, teores séricos de ferro, transferrina e ceruloplasmina, bem como ureia, creatinina e enzimas hepáticas, com o intuito de avaliar protocolos de tratamento livres de nefrotoxicidade e hepatotoxicidade para incremento dos parâmetros eritrocitários de bezerros neonatos da raça Holandesa.

\section{MATERIAL E MÉTODOS}

O delineamento experimental empregado foi aprovado pelo Comissão de Ética no Uso de Animais (CEUA) da Faculdade de Ciências Agrárias e Veterinárias (FCAV) da Universidade Estadual Paulista "Julio de Mesquita Filho" (Unesp), campus de Jaboticabal sob protocolo número 009795-08.

Foram utilizados 40 bezerros recém-nascidos da raça Holandesa, filhos de vacas pluríparas com duas a quatro gestações, provenientes de uma propriedade de produção leiteira situada no município de Monte Alto - SP, na qual havia 200 vacas em lactação, com produção média de $18 \mathrm{~kg}$ de leite/vaca/dia. 0 peso vivo médio dos bezerros ao nascimento era $32,1 \pm 1,82 \mathrm{~kg}$.

Após o nascimento, os bezerros permaneceram com as mães por aproximadamente 12 horas, e depois de receberem um volume mínimo de 4 litros de colostro por mamadeira foram transferidos para baias individuais, onde foram alimentados com um pool de leite de vaca integral proveniente das vacas em lactação, recebendo 2 litros de leite pela manhã e ao final da tarde. A partir dos 30 dias de idade foi adicionada à alimentação, ração especial para bezerros, feno e sal mineral. Aos 90 dias de idade os animais foram transferidos para o pasto, deixando de receber leite.

Os bezerros foram alocados aleatoriamente em cinco grupos experimentais, com oito animais em cada grupo, segundo o seguinte protocolo: administração intramuscular de $5 \mathrm{~mL}$ de solução 
fisiológica estéril no 5ํ dia de idade (controle G1), administração intramuscular de $5 \mathrm{~mL}$ de ferro dextrano $10 \%$ no 5 o dia de idade (G2), administração intramuscular de $5 \mathrm{~mL}$ de ferro dextrano $10 \%$ no $5^{\circ}$ e no $20^{\circ}$ dias de idade (G3), administração intramuscular de $5 \mathrm{~mL}$ de ferro dextrano $10 \%$ no $5^{\circ}$ e no 30 을 dias de idade (G4), administração intramuscular de $5 \mathrm{~mL}$ de ferro dextrano $10 \%$ no $5^{\circ}, 20^{\circ}$ e $45^{\circ}$ dias de idade (G5). A dose de ferro dextrano administrada em cada ocasião correspondeu a, aproximadamente, $15 \mathrm{mg} / \mathrm{kg}$, sendo essa a dose recomendada pelo fabricante.

Amostras de sangue foram coletadas mediante venopunção jugular, utilizando-se frascos de $5 \mathrm{~mL}$ contendo EDTA, para a realização do hemograma e $10 \mathrm{~mL}$ em frascos sem anticoagulante, para análises bioquímicas em sete momentos: até 8 horas e aos $5,10,20,30,60$ e 90 dias após o nascimento. As amostras de sangue sem anticoagulante foram centrifugadas a $1.000 \mathrm{xg}$ e o soro sanguíneo obtido foi armazenado à temperatura de $-18^{\circ} \mathrm{C}$, até o momento das análises.

De cada amostra de sangue venoso com EDTA foram aferidos os dados relativos às contagens de hemácias, ao teor de hemoglobina e a contagem de leucócitos totais em contador semiautomático (CELM CC-510, São Caetano do Sul, São Paulo, Brasil), padronizado para a espécie em estudo. O volume globular (VG) foi obtido através da técnica de microhematócrito e os índices hematimétricos (VCM, CHCM e HCM) foram calculados por meio de fórmulas matemáticas (Birgel 1982). A contagem diferencial de leucócitos foi realizada em esfregaço sanguíneo, após coloração de Rosenfeld modificada (Thrall 2007). Foram determinados os teores séricos de ferro (Goodwin et al. 1966), ureia (Bergmeyer 1985), creatinina (Burtis et al. 2007) bilirrubinas total e direta (Sims \& Horn 1958), bem como as atividades das enzimas aspartato aminotransferase (Henry et al. 1960), fosfatase alcalina (Bowers Junior \& McComb 1975) e gamaglutamiltransferase (Schumann et al. 2002), utilizando-se conjuntos de reagentes de uso comercial (Labtest Diagnóstica, Lagoa Santa, Minas Gerais). As leituras das amostras foram realizadas em espectrofotômetro semiautomático (Labquest, Labtest Diagnóstica, Lagoa Santa, Minas Gerais), com luz de comprimento de onda apropriado para cada teste $(560 \mathrm{~nm}, 340 \mathrm{~nm}, 510 \mathrm{~nm}, 525 \mathrm{~nm}, 340 \mathrm{~nm}$, $405 \mathrm{~nm}, 405 \mathrm{~nm}$, respectivamente). Os teores séricos de ceruloplasmina e transferrina foram obtidos por meio da técnica de eletroforese em gel de poliacrilamida contendo dodecil sulfato de sódio (SDS-PAGE), segundo recomendações de Laemmli (1970). Como referência foi utilizada uma solução marcadora com diferentes pesos moleculares, bem como a proteína transferrina purificada (Sigma Chemical Co., St Louis, MO, USA).

Os dados foram submetidos à análise estatística utilizando-se o programa AgroEstat 1.0 (Barbosa \& Maldonado Júnior 2008). Os valores obtidos, expressos na forma de média e desvio padrão, foram analisados pelo teste de Tukey, após a verificação da homogeneidade das amostras, sendo considerados significativos quando $\mathrm{P} \leq 0,05$.

\section{RESULTADOS}

Notou-se diminuição da contagem de hemácias nos animais do G1 a partir do nascimento, com valores menores verificados aos 60 dias de vida (Quadro 1). 0 teor de hemoglobina e o volume globular (VG) aos 30 e 60 dias de idade foram significativamente menores no G1, e maiores no G3. Notou-se também diminuição no VG a partir dos cinco dias de idade apenas no grupo controle (G1). Não foi constatada variação significativa no VCM entre grupos, porém, no G4, foi notada discreta variação entre momentos. Nos demais grupos os valores mantiveram-se estáveis com o avançar da idade. Não foi verificada diferença significativa quanto à CHCM entre grupos, porém, houve discreta oscilação dos valores entre momentos, no G2 e G3. Os valores de HCM variaram entre momentos apenas no G1 e não se constatou diferença significativa entre grupos. Não foi verificada diferença significativa entre grupos ou entre momentos quanto à contagem de leucócitos (Quadro 1).

Nos bezerros do G1 e do G2, o teor sérico de ferro não apresentou variação significativa com o avançar da idade. No G3 ocorreu diminuição significativa do teor de ferro aos 5 dias de idade, seguida de aumento no $10^{\circ}$ dia, mantendo-se estável até o 60ํ dia. No G4, o teor sérico de ferro diminuiu aos 5 dias de idade, aumentando aos 10 dias, diminuindo novamente aos 30 dias de idade. Nos grupos 1 a 4, a maior concentração de ferro foi verificada aos 90 dias de idade. No grupo 5 o maior valor foi verificado aos 60 dias de idade. Entre grupos, verificou-se que aos 60 dias de vida, o G5 apresentou teor sérico de ferro significativamente maior que os demais grupos.

Não se constatou diferença significativa nos teores séricos de ureia, bilirrubina total e bilirrubina direta entre grupos e com o avançar da idade. Em todos os grupos, os teores séricos de creatinina foram maiores logo após o nascimento, diminuindo e mantendo-se estáveis nos demais momentos. Quanto à atividade sérica da enzima AST, o maior valor foi constatado logo após o nascimento nos animais do G2. Não foi constatada variação significativa nos demais grupos e momentos (Quadro 2). Com um dia de vida, a atividade sérica da ALP foi maior nos animais do G2, já aos 60 dias de idade a atividade sérica desta enzima foi maior nos animais do G5. Também, notou-se diferença significativa entre os momentos nos grupos 1, 2 e 4, com valor máximo logo após o nascimento. Em todos os grupos, a atividade sérica de gamaglutamiltransferase (GGT) foi significativamente maior logo após a ingestão do colostro, diminuindo gradativamente com o avançar da idade.

Aos 10 e 20 dias de idade, respectivamente foram verificadas diferenças significativas quanto ao teor sérico de ceruloplasmina entre grupos, sendo que os animais do G1 apresentaram menores teores dessa proteína de fase aguda, enquanto os maiores teores foram verificados nos animais do G3 (Quadro 3). Entre momentos, nos grupos 1, 2, 3 e 5, os menores teores de ceruloplasmina foram verificados ao nascimento, e os maiores aos 90 dias (G1 e G2), 20 dias (G3) e 30 dias (G5). No G4 não foi verificada diferença entre momentos quanto aos teores de ceruloplasmina. Com relação aos teores de transferrina, logo após o nascimento, o menor valor foi verificado no G2 e o maior no G5, enquanto aos 10 dias de vida, o menor valor também foi verificado no G2 e o maior no G4. (Quadro 3). Nos grupos 1 e 4, verificaram-se oscilações entre momentos, com maior concentração sérica notada aos 5 dias de idade e menor aos 60 dias e aos 90 dias no G1 e no G4, respectivamente. Nos demais grupos (2, 3 e 5) não foi verificada diferença significativa entre momentos no decorrer do período experimental (Quadro 3).

0 efeito dos diferentes protocolos de suplementação com ferro dextrano administrado por via intramuscular foi variável, 
Quadro 1. Parâmetros eritrocitários de bezerros da raça Holandesa que receberam, por via IM, solução fisiológica estéril no 5 dia de idade (grupo 1), 5 mL de ferro dextrano $10 \%$ no 5o dia de idade (grupo 2), no 5 e no $20^{\circ}$ dias de idade (grupo 3), no 5 e no 30 dias de idade (grupo 4), no 5, no $20^{\circ}$ e no 45 dias de idade (grupo 5), logo após o nascimento (0) e com 5, 10, 20, 30, 60 e 90 dias de idade

\begin{tabular}{|c|c|c|c|c|c|}
\hline \multirow{2}{*}{$\begin{array}{l}\text { Momentos } \\
\text { (dias) }\end{array}$} & \multicolumn{5}{|c|}{ Grupos } \\
\hline & 1 & 2 & 3 & 4 & 5 \\
\hline \multicolumn{6}{|c|}{ Contagem de hemácias $\left(\mathrm{x} 10^{6} / \mu \mathrm{L}\right)$} \\
\hline 0 & $7,70 \pm 1,10 \mathrm{Aa}$ & $7,30 \pm 1,10 \mathrm{Aa}$ & $7,70 \pm 1,70 \mathrm{Aa}$ & $6,70 \pm 0,80 \mathrm{Aa}$ & $8,40 \pm 2,30 \mathrm{Aa}$ \\
\hline 5 & $7,40 \pm 2,30 \mathrm{Aa}$ & $7,20 \pm 2,00 \mathrm{Aa}$ & $7,20 \pm 1,70 \mathrm{Aa}$ & $6,30 \pm 1,10 \mathrm{Aa}$ & $8,30 \pm 2,20 \mathrm{Aa}$ \\
\hline 10 & $7,00 \pm 1,60 \mathrm{Aab}$ & $7,50 \pm 1,40 \mathrm{Aa}$ & $7,40 \pm 2,10 \mathrm{Aa}$ & $6,10 \pm 1,50 \mathrm{Aa}$ & $8,40 \pm 1,50 \mathrm{Aa}$ \\
\hline 20 & $6,90 \pm 1,80 \mathrm{Aab}$ & $7,40 \pm 2,10 \mathrm{Aa}$ & $8,00 \pm 1,80 \mathrm{Aa}$ & $6,30 \pm 1,70 \mathrm{Aa}$ & $8,80 \pm 1,90 \mathrm{Aa}$ \\
\hline 30 & $5,90 \pm 1,70 \mathrm{Aab}$ & $7,00 \pm 2,20 \mathrm{Aa}$ & $8,00 \pm 1,90 \mathrm{Aa}$ & $6,10 \pm 1,60 \mathrm{Aa}$ & $8,40 \pm 2,20 \mathrm{Aa}$ \\
\hline 60 & $5,60 \pm 2,10 \mathrm{Ab}$ & $6,90 \pm 2,30 \mathrm{Aa}$ & $7,20 \pm 2,00 \mathrm{Aa}$ & $5,90 \pm 1,70 \mathrm{Aa}$ & $7,70 \pm 2,10 \mathrm{Aa}$ \\
\hline 90 & $7,30 \pm 2,40 \mathrm{Aab}$ & $8,00 \pm 2,50 \mathrm{Aa}$ & $7,50 \pm 1,80 \mathrm{Aa}$ & $7,10 \pm 1,20 \mathrm{Aa}$ & $8,70 \pm 1,60 \mathrm{Aa}$ \\
\hline \multicolumn{6}{|c|}{ Teor de hemoglobina (g/dL) } \\
\hline 0 & $11,3 \pm 1,90 \mathrm{Aa}$ & $12,0 \pm 1,30 \mathrm{Aa}$ & $12,4 \pm 1,70 \mathrm{Aa}$ & $10,8 \pm 1,20 \mathrm{Aa}$ & $12,2 \pm 2,70 \mathrm{Aa}$ \\
\hline 5 & $11,0 \pm 2,30 \mathrm{Aa}$ & $11,7 \pm 1,30 \mathrm{Aa}$ & $11,8 \pm 2,20 \mathrm{Aa}$ & $10,5 \pm 1,00 \mathrm{Aa}$ & $11,7 \pm 2,70 \mathrm{Aa}$ \\
\hline 10 & $11,1 \pm 2,00 \mathrm{Aa}$ & $12,2 \pm 1,50 \mathrm{Aa}$ & $12,3 \pm 2,30 \mathrm{Aa}$ & $10,4 \pm 0,80 \mathrm{Aa}$ & $12,1 \pm 1,90 \mathrm{Aa}$ \\
\hline 20 & $10,4 \pm 2,20 \mathrm{Aa}$ & $12,2 \pm 1,10 \mathrm{Aa}$ & $12,4 \pm 2,00 \mathrm{Aa}$ & $10,5 \pm 1,00 \mathrm{Aa}$ & $12,5 \pm 1,70 \mathrm{Aa}$ \\
\hline 30 & $9,70 \pm 2,00 \mathrm{Ba}$ & $11,8 \pm 1,30 \mathrm{ABa}$ & $12,6 \pm 1,90 \mathrm{Aa}$ & $11,0 \pm 1,60 \mathrm{ABa}$ & $11,7 \pm 2,00 \mathrm{ABa}$ \\
\hline 60 & $9,40 \pm 1,80 \mathrm{Ba}$ & $10,9 \pm 1,00 \mathrm{ABa}$ & $12,0 \pm 2,60 \mathrm{Aa}$ & $9,60 \pm 1,70 \mathrm{ABa}$ & $10,9 \pm 2,00 \mathrm{ABa}$ \\
\hline 90 & $11,2 \pm 2,50 \mathrm{Aa}$ & $12,5 \pm 1,60 \mathrm{Aa}$ & $12,5 \pm 1,90 \mathrm{Aa}$ & $11,0 \pm 2,40 \mathrm{Aa}$ & $12,3 \pm 1,50 \mathrm{Aa}$ \\
\hline \multicolumn{6}{|c|}{ VG (\%) } \\
\hline 0 & $36 \pm 5,1 \mathrm{Aa}$ & $38 \pm 3,9 \mathrm{Aa}$ & $39 \pm 4,2 \mathrm{Aa}$ & $35 \pm 4,4 \mathrm{Aa}$ & $39 \pm 8,4 \mathrm{Aa}$ \\
\hline 5 & $34 \pm 7,3 \mathrm{Aab}$ & $37 \pm 3,9$ Aа & $38 \pm 6,0 \mathrm{Aa}$ & $33 \pm 3,4 \mathrm{Aa}$ & $36 \pm 9,9 \mathrm{Aa}$ \\
\hline 10 & $34 \pm 5,2 \mathrm{Aab}$ & $39 \pm 4,6$ Аа & $39 \pm 4,5 \mathrm{Aa}$ & $32 \pm 4,3 \mathrm{Aa}$ & $37 \pm 5,2 \mathrm{Aa}$ \\
\hline 20 & $33 \pm 6,8 \mathrm{Aab}$ & $39 \pm 4,6 \mathrm{Aa}$ & $39 \pm 5,5 \mathrm{Aa}$ & $33 \pm 3,7 \mathrm{Aa}$ & $39 \pm 5,2 \mathrm{Aa}$ \\
\hline 30 & $30 \pm 6,3 \mathrm{Bab}$ & $37 \pm 3,5 \mathrm{ABa}$ & $39 \pm 6,0 \mathrm{Aa}$ & $34 \pm 3,0 \mathrm{ABa}$ & $35 \pm 6,3 \mathrm{ABa}$ \\
\hline 60 & $28 \pm 5,2 \mathrm{Bb}$ & $33 \pm 3,3 \mathrm{ABa}$ & $37 \pm 7,3 \mathrm{Aa}$ & $29 \pm 4,9 \mathrm{ABa}$ & $35 \pm 6,5 \mathrm{ABa}$ \\
\hline 90 & $33 \pm 6,6 \mathrm{Aab}$ & $36 \pm 3,5 \mathrm{Aa}$ & $36 \pm 6,2 \mathrm{Aa}$ & $33 \pm 7,1 \mathrm{Aa}$ & $37 \pm 4,5 \mathrm{Aa}$ \\
\hline \multicolumn{6}{|c|}{ VCM (fL) } \\
\hline 0 & $47 \pm 3,4 \mathrm{Aa}$ & $53 \pm 8,1 \mathrm{Aa}$ & $53 \pm 9,6$ Aа & $53 \pm 6,6 \mathrm{Aab}$ & $48 \pm 7,8 \mathrm{Aa}$ \\
\hline 5 & $48 \pm 13 \mathrm{Aa}$ & $55 \pm 13 \mathrm{Aa}$ & $54 \pm 6,2 \mathrm{Aa}$ & $55 \pm 13 \mathrm{Aab}$ & $43 \pm 4,4 \mathrm{Aa}$ \\
\hline 10 & $51 \pm 12 \mathrm{Aa}$ & $54 \pm 7,3 \mathrm{Aa}$ & $56 \pm 13 \mathrm{Aa}$ & $55 \pm 15 \mathrm{Aab}$ & $45 \pm 3,8 \mathrm{Aa}$ \\
\hline 20 & $49 \pm 13 \mathrm{Aa}$ & $57 \pm 17 \mathrm{Aa}$ & $49 \pm 8,9$ Аа & $56 \pm 16 \mathrm{Aab}$ & $45 \pm 9,0 \mathrm{Aa}$ \\
\hline 30 & $55 \pm 21 \mathrm{Aa}$ & $56 \pm 20 \mathrm{Aa}$ & $50 \pm 11 \mathrm{Aa}$ & $61 \pm 20,4 \mathrm{Aa}$ & $43 \pm 8,5 \mathrm{Aa}$ \\
\hline 60 & $54 \pm 19$ Aа & $53 \pm 22 \mathrm{Aa}$ & $53 \pm 11 \mathrm{Aa}$ & $52 \pm 12 \mathrm{Aab}$ & $47 \pm 9,8 \mathrm{Aa}$ \\
\hline 90 & $47 \pm 9,6 \mathrm{Aa}$ & $50 \pm 18 \mathrm{Aa}$ & $50 \pm 13 \mathrm{Aa}$ & $49 \pm 15 \mathrm{Ab}$ & $44 \pm 7,5 \mathrm{Aa}$ \\
\hline \multicolumn{6}{|c|}{ CHCM (g/dL) } \\
\hline 0 & $32 \pm 1,3 \mathrm{Aa}$ & $32 \pm 2,1 \mathrm{Aab}$ & $32 \pm 1,3 \mathrm{Ab}$ & $31 \pm 1,7 \mathrm{Aa}$ & $31 \pm 1,7 \mathrm{Aa}$ \\
\hline 5 & $33 \pm 0,8 \mathrm{Aa}$ & $32 \pm 1,4 \mathrm{Ab}$ & $31 \pm 1,5 \mathrm{Ab}$ & $32 \pm 1,3 \mathrm{Aa}$ & $33 \pm 2,9 \mathrm{Aa}$ \\
\hline 10 & $33 \pm 1,2 \mathrm{Aa}$ & $31 \pm 1,7 \mathrm{Ab}$ & $31 \pm 3,5 \mathrm{Ab}$ & $33 \pm 2,3 \mathrm{Aa}$ & $32 \pm 1,4 \mathrm{Aa}$ \\
\hline 20 & $32 \pm 1,1 \mathrm{Aa}$ & $31 \pm 1,4 \mathrm{Ab}$ & $32 \pm 1,1 \mathrm{Aab}$ & $32 \pm 1,1 \mathrm{Aa}$ & $32 \pm 1,2 \mathrm{Aa}$ \\
\hline 30 & $32 \pm 2,7 \mathrm{Aa}$ & $32 \pm 1,5 \mathrm{Ab}$ & $32 \pm 1,8 \mathrm{Aab}$ & $32 \pm 4,8 \mathrm{Aa}$ & $33 \pm 2,4 \mathrm{Aa}$ \\
\hline 60 & $34 \pm 1,4 \mathrm{Aa}$ & $33 \pm 1,2 \mathrm{Aab}$ & $33 \pm 1,5 \mathrm{Aab}$ & $33 \pm 1,4 \mathrm{Aa}$ & $32 \pm 2,3 \mathrm{Aa}$ \\
\hline 90 & $34 \pm 1,2 \mathrm{Aa}$ & $35 \pm 2,3 \mathrm{Aa}$ & $35 \pm 2,6 \mathrm{Aa}$ & $33 \pm 1,9 \mathrm{Aa}$ & $33 \pm 1,1 \mathrm{Aa}$ \\
\hline \multicolumn{6}{|c|}{ HCM (pg) } \\
\hline 0 & $15 \pm 1,1 \mathrm{Ab}$ & $17 \pm 3,0 \mathrm{Aa}$ & $17 \pm 2,6$ Aa & $16 \pm 1,7 \mathrm{Aa}$ & $15 \pm 2,5 \mathrm{Aa}$ \\
\hline 5 & $16 \pm 3,8 \mathrm{Aab}$ & $17 \pm 4,2 \mathrm{Aa}$ & $17 \pm 1,7 \mathrm{Aa}$ & $17 \pm 3,7 \mathrm{Aa}$ & $14 \pm 1,0 \mathrm{Aa}$ \\
\hline 10 & $17 \pm 3,9 \mathrm{Aab}$ & $17 \pm 2,8 \mathrm{Aa}$ & $17 \pm 3,3$ Аа & $18 \pm 4,6 \mathrm{Aa}$ & $14 \pm 1,2 \mathrm{Aa}$ \\
\hline 20 & $16 \pm 4,0 \mathrm{Aab}$ & $18 \pm 5,3 \mathrm{Aa}$ & $16 \pm 2,7 \mathrm{Aa}$ & $18 \pm 4,9 \mathrm{Aa}$ & $15 \pm 2,8 \mathrm{Aa}$ \\
\hline 30 & $18 \pm 6,0 \mathrm{Aab}$ & $18 \pm 6,8 \mathrm{Aa}$ & $16 \pm 3,3 \mathrm{Aa}$ & $19 \pm 4,6$ Аа & $14 \pm 2,4 \mathrm{Aa}$ \\
\hline 60 & $18 \pm 5,7 \mathrm{Aa}$ & $18 \pm 6,9 \mathrm{Aa}$ & $17 \pm 3,7 \mathrm{Aa}$ & $17 \pm 4,0 \mathrm{Aa}$ & $15 \pm 2,6 \mathrm{Aa}$ \\
\hline 90 & $16 \pm 3,2 \mathrm{Aab}$ & $18 \pm 7,1 \mathrm{Aa}$ & $17 \pm 4,3 \mathrm{Aa}$ & $16 \pm 4,7 \mathrm{Aa}$ & $15 \pm 2,5 \mathrm{Aa}$ \\
\hline
\end{tabular}

Letras maiúsculas diferentes indicam diferenças entre grupos e letras minúsculas diferentes indicam diferenças entre momentos $(\mathrm{P} \leq 0,05)$. 
Quadro 1. Continuação...

\begin{tabular}{|c|c|c|c|c|c|}
\hline \multirow{2}{*}{$\begin{array}{l}\text { Momentos } \\
\text { (dias) }\end{array}$} & \multicolumn{5}{|c|}{ Grupos } \\
\hline & 1 & 2 & 3 & 4 & 5 \\
\hline \multicolumn{6}{|c|}{ Leucócitos totais $\left(\mathrm{x} 10^{3} / \mu \mathrm{L}\right)$} \\
\hline 0 & $11,3 \pm 2,7 \mathrm{Aa}$ & $7,0 \pm 2,7 \mathrm{Aa}$ & $10,6 \pm 3,8 \mathrm{Aa}$ & $9,1 \pm 3,1 \mathrm{Aa}$ & $9,7 \pm 4,8 \mathrm{Aa}$ \\
\hline 5 & $9,4 \pm 3,3$ Aa & $8,4 \pm 3,9 \mathrm{Aa}$ & $8,8 \pm 3,9$ Aa & $7,9 \pm 4,4$ Aa & $9,5 \pm 3,3$ Aa \\
\hline 10 & $11,1 \pm 3,0$ Аa & $9,0 \pm 2,2 \mathrm{Aa}$ & $9,4 \pm 5,2 \mathrm{Aa}$ & $7,6 \pm 1,8 \mathrm{Aa}$ & $10,1 \pm 3,2 \mathrm{Aa}$ \\
\hline 20 & $8,8 \pm 2,2$ Aa & $8,7 \pm 4,0 \mathrm{Aa}$ & $10,2 \pm 4,9 \mathrm{Aa}$ & $8,3 \pm 2,6 \mathrm{Aa}$ & $10,2 \pm 3,2 \mathrm{Aa}$ \\
\hline 30 & $10,0 \pm 2,8 \mathrm{Aa}$ & $8,3 \pm 2,1$ Aa & $9,5 \pm 2,3$ Aa & $9,9 \pm 3,2$ Aа & $11,2 \pm 3,1 \mathrm{Aa}$ \\
\hline 60 & $10,3 \pm 2,9 \mathrm{Aa}$ & $8,0 \pm 1,9 \mathrm{Aa}$ & $10,3 \pm 3,0 \mathrm{Aa}$ & $8,7 \pm 2,1 \mathrm{Aa}$ & $11,4 \pm 3,2$ Аа \\
\hline 90 & $11,7 \pm 3,9$ Аа & $10,0 \pm 4,7 \mathrm{Aa}$ & $9,9 \pm 3,1 \mathrm{Aa}$ & $10,6 \pm 3,0$ Аа & $11,0 \pm 1,9$ Аа \\
\hline \multicolumn{6}{|c|}{ Neutrófilos segmentados $\left(\mathrm{x} 10^{3} / \mu \mathrm{L}\right)$} \\
\hline 0 & $7,0 \pm 2,8 \mathrm{Aa}$ & $5,0 \pm 3,7 \mathrm{Aa}$ & $7,2 \pm 2,5 \mathrm{Aa}$ & $6,2 \pm 2,7 \mathrm{Aa}$ & $6,8 \pm 4,7 \mathrm{Aa}$ \\
\hline 5 & $4,0 \pm 2,6 \mathrm{Aab}$ & $4,0 \pm 2,2 \mathrm{Aa}$ & $4,9 \pm 3,8 \mathrm{Aab}$ & $3,2 \pm 1,9 \mathrm{Aab}$ & $5,3 \pm 3,5 \mathrm{Aab}$ \\
\hline 10 & $5,6 \pm 2,1 \mathrm{Aab}$ & $3,9 \pm 1,7 \mathrm{Aa}$ & $5,2 \pm 4,4 \mathrm{Aab}$ & $2,4 \pm 0,92 \mathrm{Ab}$ & $5,5 \pm 2,4 \mathrm{Aab}$ \\
\hline 20 & $2,8 \pm 1,4 \mathrm{Ab}$ & $3,9 \pm 4,2 \mathrm{Aa}$ & $5,1 \pm 3,8 \mathrm{Aab}$ & $2,7 \pm 1,3 \mathrm{Aab}$ & $3,8 \pm 2,5$ Aab \\
\hline 30 & $4,3 \pm 2,4 \mathrm{Aab}$ & $2,7 \pm 1,1 \mathrm{Aa}$ & $4,8 \pm 2,3 \mathrm{Aab}$ & $3,3 \pm 2,0 \mathrm{Aab}$ & $4,1 \pm 2,9$ Aab \\
\hline 60 & $3,2 \pm 2,0 \mathrm{Ab}$ & $3,4 \pm 2,2 \mathrm{Aa}$ & $3,2 \pm 1,8 \mathrm{Ab}$ & $2,4 \pm 1,8 \mathrm{Ab}$ & $3,4 \pm 1,7 \mathrm{Aab}$ \\
\hline 90 & $4,0 \pm 4,8 \mathrm{Aab}$ & $3,7 \pm 3,3 \mathrm{Aa}$ & $3,5 \pm 3,3 \mathrm{Ab}$ & $3,0 \pm 1,5 \mathrm{Aab}$ & $2,6 \pm 1,1 \mathrm{Ab}$ \\
\hline \multicolumn{6}{|c|}{ Linfócitos $\left(\mathrm{x} 10^{3} / \mu \mathrm{L}\right)$} \\
\hline 0 & $4,2 \pm 3,5 \mathrm{Aa}$ & $3,4 \pm 2,6 \mathrm{Aa}$ & $3,3 \pm 2,5 \mathrm{Ac}$ & $2,7 \pm 1,8 \mathrm{Ac}$ & $2,7 \pm 1,3$ Ac \\
\hline 5 & $5,2 \pm 2,3$ Aа & $3,6 \pm 1,6 \mathrm{Aa}$ & $3,7 \pm 2,3 \mathrm{Abc}$ & $4,5 \pm 2,8 \mathrm{Abc}$ & $4,2 \pm 1,4 \mathrm{Abc}$ \\
\hline 10 & $5,5 \pm 2,8 \mathrm{Aa}$ & $4,9 \pm 2,2 \mathrm{Aa}$ & $3,9 \pm 2,1 \mathrm{Abc}$ & $5,1 \pm 1,3$ Aabc & $4,5 \pm 1,8 \mathrm{Abc}$ \\
\hline 20 & $5,9 \pm 1,5$ Аа & $5,9 \pm 3,7 \mathrm{Aa}$ & $5,0 \pm 3,2$ Aabc & $5,5 \pm 1,4$ Aab & $6,2 \pm 1,1 \mathrm{Aab}$ \\
\hline 30 & $5,5 \pm 2,0 \mathrm{Aa}$ & $5,4 \pm 1,2 \mathrm{Aa}$ & $4,5 \pm 1,9$ Aabc & $6,4 \pm 2,4 \mathrm{Aab}$ & $6,9 \pm 2,6 \mathrm{Aab}$ \\
\hline 60 & $6,7 \pm 1,9$ Аа & $5,9 \pm 3,3 \mathrm{Aa}$ & $6,8 \pm 2,7 \mathrm{Aa}$ & $6,3 \pm 1,6 \mathrm{Aab}$ & $7,9 \pm 1,8 \mathrm{Aa}$ \\
\hline 90 & $5,7 \pm 3,6 \mathrm{Aa}$ & $5,8 \pm 2,5 \mathrm{Aa}$ & $6,1 \pm 1,4$ Aab & $7,5 \pm 2,4 \mathrm{Aa}$ & $8,2 \pm 1,7 \mathrm{Aa}$ \\
\hline
\end{tabular}

Letras maiúsculas diferentes indicam diferenças entre grupos e letras minúsculas diferentes indicam diferenças entre momentos (P $\leq 0,05)$.

Quadro 2. Teores séricos de ferro, ureia, creatinina, bilirrubina total e direta, atividades de aspartato aminotransferase, fosfatase alcalina e gamaglutamiltransferase de bezerros da raça Holandesa que receberam, por via IM, solução fisiológica estéril no $5^{\circ}$ dia de idade (grupo 1), $5 \mathrm{~mL}$ de ferro dextrano $10 \%$ no 5 o dia de idade (grupo 2), no 5o e no $20^{\circ}$ dias de idade (grupo 3), no 5 e no 30 o dias de idade (grupo 4), no 5ㅜㅜ, no $20^{\circ}$ e no 45 dias de idade (grupo 5), logo após o nascimento (0) e com 5, 10, 20, 30, 60 e 90 dias de idade

\begin{tabular}{|c|c|c|c|c|c|}
\hline \multirow{2}{*}{$\begin{array}{l}\text { Momentos } \\
\text { (dias) }\end{array}$} & \multicolumn{5}{|c|}{ Grupos } \\
\hline & 1 & 2 & 3 & 4 & 5 \\
\hline \multicolumn{6}{|c|}{ Ferro $(\mu \mathrm{g} / \mathrm{dL})$} \\
\hline 0 & $114 \pm 38$ Aa & $144 \pm 60 \mathrm{Aa}$ & $163 \pm 76 \mathrm{Aab}$ & $128 \pm 77 \mathrm{Aab}$ & $118 \pm 71 \mathrm{Abc}$ \\
\hline 5 & $101 \pm 37 \mathrm{Aa}$ & $151 \pm 135$ Aа & $87 \pm 35 \mathrm{Ab}$ & $92 \pm 41 \mathrm{Ab}$ & $73,8 \pm 30 \mathrm{Ac}$ \\
\hline 10 & $119 \pm 35 \mathrm{Aa}$ & $113 \pm 54$ Aa & $130 \pm 45 \mathrm{Aab}$ & $174 \pm 68 \mathrm{Aab}$ & $143 \pm 75 \mathrm{Abc}$ \\
\hline 20 & $127 \pm 51 \mathrm{Aa}$ & $155 \pm 59$ Аа & $117 \pm 55 \mathrm{Aab}$ & $185 \pm 59 \mathrm{Aa}$ & $162 \pm 77 \mathrm{Aab}$ \\
\hline 30 & $147 \pm 52 \mathrm{Aa}$ & $167 \pm 53 \mathrm{Aa}$ & $144 \pm 46 \mathrm{Aab}$ & $142 \pm 40 \mathrm{Aab}$ & $139 \pm 106 \mathrm{Abc} \mathrm{Abc}$ \\
\hline 60 & $96 \pm 58 \mathrm{Ba}$ & $124 \pm 43 \mathrm{Ba}$ & $148 \pm 80 \mathrm{Bab}$ & $150 \pm 46 \mathrm{Bab}$ & $245 \pm 90$ Aа \\
\hline 90 & $159 \pm 50 \mathrm{Aa}$ & $182 \pm 65 \mathrm{Aa}$ & $190 \pm 48$ Aа & $207 \pm 57 \mathrm{Aa}$ & $155 \pm 45 \mathrm{Abc}$ \\
\hline \multicolumn{6}{|c|}{ Ureia (mg/dL) } \\
\hline 0 & $23 \pm 7,1 \mathrm{Aa}$ & $18 \pm 8,9$ Aа & $18 \pm 6,2 \mathrm{Aa}$ & $21 \pm 8,72 \mathrm{Aa}$ & $20 \pm 13 \mathrm{Aa}$ \\
\hline 5 & $25 \pm 8,1 \mathrm{Aa}$ & $19 \pm 7,5 \mathrm{Aa}$ & $24 \pm 10 \mathrm{Aa}$ & $22 \pm 6,7 \mathrm{Aa}$ & $22 \pm 5,2 \mathrm{Aa}$ \\
\hline 10 & $25 \pm 8,5 \mathrm{Aa}$ & $24 \pm 8,8 \mathrm{Aa}$ & $28 \pm 2,3 \mathrm{Aa}$ & $25 \pm 6,2 \mathrm{Aa}$ & $25 \pm 18$ Aa \\
\hline 20 & $23 \pm 5,0 \mathrm{Aa}$ & $26 \pm 10 \mathrm{Aa}$ & $25 \pm 8,3 \mathrm{Aa}$ & $20 \pm 6,0 \mathrm{Aa}$ & $22 \pm 6,4 \mathrm{Aa}$ \\
\hline 30 & $30 \pm 15$ Aa & $23 \pm 5,1 \mathrm{Aa}$ & $20 \pm 5,8 \mathrm{Aa}$ & $20 \pm 5,1 \mathrm{Aa}$ & $16 \pm 3,1 \mathrm{Aa}$ \\
\hline 60 & $28 \pm 14$ Aa & $24 \pm 13$ Aa & $20 \pm 5,3 \mathrm{Aa}$ & $25 \pm 7,7 \mathrm{Aa}$ & $23 \pm 4,9 \mathrm{Aa}$ \\
\hline 90 & $30 \pm 25 \mathrm{Aa}$ & $25 \pm 24 \mathrm{Aa}$ & $24 \pm 8,6 \mathrm{Aa}$ & $31 \pm 17 \mathrm{Aa}$ & $20 \pm 4,3 \mathrm{Aa}$ \\
\hline
\end{tabular}

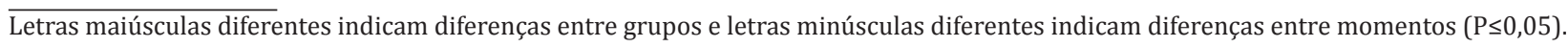


Quadro 2. Continuação...

\begin{tabular}{|c|c|c|c|c|c|}
\hline \multirow{2}{*}{$\begin{array}{l}\text { Momentos } \\
\text { (dias) }\end{array}$} & \multicolumn{5}{|c|}{ Grupos } \\
\hline & 1 & 2 & 3 & 4 & 5 \\
\hline \multicolumn{6}{|c|}{ Creatinina (mg/dL) } \\
\hline 0 & $1,90 \pm 0,49 \mathrm{Aa}$ & $1,74 \pm 0,80 \mathrm{Aa}$ & $1,82 \pm 0,97 \mathrm{Aa}$ & $1,52 \pm 0,41 \mathrm{Aa}$ & $1,67 \pm 0,49 \mathrm{Aa}$ \\
\hline 5 & $1,28 \pm 0,25 \mathrm{Ab}$ & $1,09 \pm 0,36 \mathrm{Ab}$ & $1,05 \pm 0,57 \mathrm{Ab}$ & $1,10 \pm 0,12 \mathrm{Ab}$ & $1,11 \pm 0,17 \mathrm{Ab}$ \\
\hline 10 & $1,29 \pm 0,22 \mathrm{Ab}$ & $0,99 \pm 0,43 \mathrm{Ab}$ & $0,96 \pm 0,57 \mathrm{Ab}$ & $1,2 \pm 0,11 \mathrm{Aab}$ & $1,09 \pm 0,16 \mathrm{Ab}$ \\
\hline 20 & $1,23 \pm 0,22 \mathrm{Ab}$ & $1,03 \pm 0,45 \mathrm{Ab}$ & $0,87 \pm 0,47 \mathrm{Ab}$ & $1,07 \pm 0,11 \mathrm{Ab}$ & $1,07 \pm 0,15 \mathrm{Ab}$ \\
\hline 30 & $1,22 \pm 0,37 \mathrm{Ab}$ & $0,99 \pm 0,44 \mathrm{Ab}$ & $0,78 \pm 0,42 \mathrm{Ab}$ & $1,12 \pm 0,13 \mathrm{Ab}$ & $1,02 \pm 0,15 \mathrm{Ab}$ \\
\hline 60 & $1,09 \pm 0,26 \mathrm{Ab}$ & $0,90 \pm 0,40 \mathrm{Ab}$ & $0,80 \pm 0,39 \mathrm{Ab}$ & $1,01 \pm 0,07 \mathrm{Ab}$ & $1,03 \pm 0,16 \mathrm{Ab}$ \\
\hline 90 & $0,94 \pm 0,10 \mathrm{Ab}$ & $0,81 \pm 0,48 \mathrm{Ab}$ & $0,74 \pm 0,34 \mathrm{Ab}$ & $0,97 \pm 0,10 \mathrm{Ab}$ & $1,11 \pm 0,15 \mathrm{Ab}$ \\
\hline \multicolumn{6}{|c|}{ Bilirrubina total (mg/dL) } \\
\hline 0 & $0,69 \pm 0,23 \mathrm{Aa}$ & $0,78 \pm 0,32 \mathrm{Aa}$ & $0,59 \pm 0,27 \mathrm{Aa}$ & $0,80 \pm 0,42 \mathrm{Aa}$ & $0,65 \pm 0,39 \mathrm{Aa}$ \\
\hline 5 & $0,48 \pm 0,15 \mathrm{Aa}$ & $0,42 \pm 0,16 \mathrm{Aa}$ & $0,38 \pm 0,07 \mathrm{Aa}$ & $0,41 \pm 0,19 \mathrm{Aa}$ & $0,38 \pm 0,20 \mathrm{Aa}$ \\
\hline 10 & $0,44 \pm 0,13 \mathrm{Aa}$ & $0,42 \pm 0,12 \mathrm{Aa}$ & $0,31 \pm 0,10 \mathrm{Aa}$ & $0,33 \pm 0,14 \mathrm{Aa}$ & $0,43 \pm 0,09 \mathrm{Aa}$ \\
\hline 20 & $0,36 \pm 0,09 \mathrm{Aa}$ & $0,40 \pm 0,14 \mathrm{Aa}$ & $0,28 \pm 0,10 \mathrm{Aa}$ & $0,34 \pm 0,09 \mathrm{Aa}$ & $0,38 \pm 0,13 \mathrm{Aa}$ \\
\hline 30 & $0,50 \pm 0,17 \mathrm{Aa}$ & $0,38 \pm 0,17 \mathrm{Aa}$ & $0,30 \pm 0,04 \mathrm{Aa}$ & $0,33 \pm 0,14 \mathrm{Aa}$ & $0,33 \pm 0,11 \mathrm{Aa}$ \\
\hline 60 & $0,48 \pm 0,09 \mathrm{Aa}$ & $0,31 \pm 0,09 \mathrm{Aa}$ & $0,40 \pm 0,30 \mathrm{Aa}$ & $0,37 \pm 0,16 \mathrm{Aa}$ & $0,48 \pm 0,13 \mathrm{Aa}$ \\
\hline 90 & $0,36 \pm 0,15 \mathrm{Aa}$ & $0,28 \pm 0,11 \mathrm{Aa}$ & $0,29 \pm 0,10 \mathrm{Aa}$ & $0,29 \pm 0,11 \mathrm{Aa}$ & $0,31 \pm 0,11 \mathrm{Aa}$ \\
\hline \multicolumn{6}{|c|}{ Bilirrubina direta $(\mathrm{mg} / \mathrm{dL})$} \\
\hline 0 & $0,25 \pm 0,13 \mathrm{Aa}$ & $0,28 \pm 0,13 \mathrm{Aa}$ & $0,23 \pm 0,11 \mathrm{Aa}$ & $0,19 \pm 0,11 \mathrm{Aa}$ & $0,19 \pm 0,16 \mathrm{Aa}$ \\
\hline 5 & $0,13 \pm 0,07 \mathrm{Aab}$ & $0,17 \pm 0,10 \mathrm{Aab}$ & $0,15 \pm 0,06 \mathrm{Aab}$ & $0,11 \pm 0,11 \mathrm{Aab}$ & $0,11 \pm 0,11$ Aab \\
\hline 10 & $0,15 \pm 0,08 \mathrm{Aab}$ & $0,14 \pm 0,07 \mathrm{Ab}$ & $0,13 \pm 0,07 \mathrm{Aab}$ & $0,07 \pm 0,05 \mathrm{Ab}$ & $0,09 \pm 0,07 \mathrm{Aab}$ \\
\hline 20 & $0,10 \pm 0,05 \mathrm{Ab}$ & $0,15 \pm 0,06 \mathrm{Ab}$ & $0,10 \pm 0,07 \mathrm{Ab}$ & $0,07 \pm 0,07 \mathrm{Ab}$ & $0,08 \pm 0,06 \mathrm{Ab}$ \\
\hline 30 & $0,14 \pm 0,11 \mathrm{Aab}$ & $0,11 \pm 0,11 \mathrm{Ab}$ & $0,11 \pm 0,04 \mathrm{Ab}$ & $0,07 \pm 0,04 \mathrm{Ab}$ & $0,08 \pm 0,05 \mathrm{Ab}$ \\
\hline 60 & $0,20 \pm 0,12 \mathrm{Aab}$ & $0,09 \pm 0,05 \mathrm{Ab}$ & $0,14 \pm 0,11 \mathrm{Aab}$ & $0,08 \pm 0,05 \mathrm{Aab}$ & $0,10 \pm 0,06 \mathrm{Aab}$ \\
\hline 90 & $0,16 \pm 0,12 \mathrm{Aab}$ & $0,09 \pm 0,05 \mathrm{Ab}$ & $0,09 \pm 0,05 \mathrm{Ab}$ & $0,07 \pm 0,04 \mathrm{Ab}$ & $0,14 \pm 0,14 \mathrm{Aa}$ \\
\hline \multicolumn{6}{|c|}{ Aspartato aminotransferase (U/L) } \\
\hline 0 & $62,3 \pm 25,2 \mathrm{Ba}$ & $240 \pm 487 \mathrm{Aa}$ & $57,0 \pm 21,8 \mathrm{Ba}$ & $51,1 \pm 32,6 \mathrm{Ba}$ & $55,7 \pm 24,7 \mathrm{Ba}$ \\
\hline 5 & $33,4 \pm 6,82 \mathrm{Aa}$ & $38,0 \pm 12,8 \mathrm{Ab}$ & $41,2 \pm 16,2 \mathrm{Aa}$ & $30,1 \pm 6,72 \mathrm{Aa}$ & $32,1 \pm 5,90 \mathrm{Aa}$ \\
\hline 10 & $34,7 \pm 7,86 \mathrm{Aa}$ & $45,8 \pm 17,7 \mathrm{Ab}$ & $34,0 \pm 5,60 \mathrm{Aa}$ & $31,4 \pm 5,60 \mathrm{Aa}$ & $39,9 \pm 11,5 \mathrm{Aa}$ \\
\hline 20 & $37,3 \pm 5,90 \mathrm{Aa}$ & $39,9 \pm 12,2 \mathrm{Ab}$ & $44,5 \pm 12,5 \mathrm{Aa}$ & $38,0 \pm 11,8 \mathrm{Aa}$ & $43,9 \pm 11,2 \mathrm{Aa}$ \\
\hline 30 & $39,9 \pm 11,2 \mathrm{Aa}$ & $45,2 \pm 10,5 \mathrm{Ab}$ & $49,1 \pm 21,5 \mathrm{Aa}$ & $43,9 \pm 11,2 \mathrm{Aa}$ & $42,6 \pm 9,87 \mathrm{Aa}$ \\
\hline 60 & $49,1 \pm 10,5 \mathrm{Aa}$ & $68,1 \pm 67,1 \mathrm{Ab}$ & $77,7 \pm 58,0 \mathrm{Aa}$ & $45,8 \pm 15,0 \mathrm{Aa}$ & $48,5 \pm 12,6 \mathrm{Aa}$ \\
\hline 90 & $53,0 \pm 15,2 \mathrm{Aa}$ & $49,1 \pm 13,4 \mathrm{Ab}$ & $62,9 \pm 16,3 \mathrm{Aa}$ & $47,8 \pm 13,3 \mathrm{Aa}$ & $47,3 \pm 18,8 \mathrm{Aa}$ \\
\hline \multicolumn{6}{|c|}{ Fosfatase alcalina (U/L) } \\
\hline 0 & $334 \pm 135 \mathrm{Ba}$ & $530 \pm 226 \mathrm{Aa}$ & $184 \pm 92,3 \mathrm{Ca}$ & $277 \pm 143 \mathrm{BCa}$ & $245 \pm 99,3 \mathrm{BCa}$ \\
\hline 5 & $243 \pm 91,4 \mathrm{Aab}$ & $291 \pm 81,2 \mathrm{Ab}$ & $182 \pm 84,3 \mathrm{Aa}$ & $211 \pm 108 \mathrm{Aab}$ & $189 \pm 68,9 \mathrm{Aa}$ \\
\hline 10 & $227 \pm 101 \mathrm{Aab}$ & $215 \pm 45,7 \mathrm{Ab}$ & $121 \pm 59,0 \mathrm{Aa}$ & $170 \pm 56,6 \mathrm{Aab}$ & $184 \pm 52,8$ Aa \\
\hline 20 & $176 \pm 74,4 \mathrm{Ab}$ & $244 \pm 71,2 \mathrm{Ab}$ & $137 \pm 74,3 \mathrm{Aa}$ & $209 \pm 104 \mathrm{Ab}$ & $230 \pm 93,6$ Аа \\
\hline 30 & $163 \pm 75,1 \mathrm{Ab}$ & $253 \pm 73,0 \mathrm{Ab}$ & $138 \pm 72,6$ Aа & $150 \pm 84,1 \mathrm{Aab}$ & $195 \pm 107 \mathrm{Aa}$ \\
\hline 60 & $182 \pm 93,2 \mathrm{ABb}$ & $242 \pm 97,9 \mathrm{ABb}$ & $122 \pm 54,2 \mathrm{Ba}$ & $184 \pm 68,0 \mathrm{ABab}$ & $265 \pm 113$ Аа \\
\hline 90 & $152 \pm 70,9 \mathrm{Ab}$ & $202 \pm 73,8 \mathrm{Ab}$ & $178 \pm 64,8 \mathrm{Aa}$ & $174 \pm 63,7 \mathrm{Aab}$ & $197 \pm 109$ Аа \\
\hline
\end{tabular}

Letras maiúsculas diferentes indicam diferenças entre grupos e letras minúsculas diferentes indicam diferenças entre momentos $(\mathrm{P} \leq 0,05)$. 
Quadro 2. Continuação...

\begin{tabular}{|c|c|c|c|c|c|}
\hline \multirow{2}{*}{$\begin{array}{l}\text { Momentos } \\
\text { (dias) }\end{array}$} & \multicolumn{5}{|c|}{ Grupos } \\
\hline & 1 & 2 & 3 & 4 & 5 \\
\hline \multicolumn{6}{|c|}{ Gamaglutamiltransferase (U/L) } \\
\hline 0 & $857 \pm 797 \mathrm{BCa}$ & $1.399 \pm 686 \mathrm{Aa}$ & $544 \pm 555 \mathrm{CDa}$ & $375 \pm 316 \mathrm{Da}$ & $1.008 \pm 1.258 \mathrm{ABa}$ \\
\hline 5 & $151 \pm 102 \mathrm{Ab}$ & $247 \pm 207 \mathrm{Ab}$ & $137 \pm 99,3 \mathrm{Aab}$ & $174 \pm 79,8 \mathrm{Aa}$ & $321 \pm 392 \mathrm{Ab}$ \\
\hline 10 & $89,5 \pm 63,3 \mathrm{Ab}$ & $154 \pm 84,5 \mathrm{Ab}$ & $63,1 \pm 29,7 \mathrm{Ab}$ & $92,8 \pm 52,6$ Aa & $123 \pm 131 \mathrm{Ab}$ \\
\hline 20 & $40,3 \pm 22,9 \mathrm{Ab}$ & $126 \pm 164 \mathrm{Ab}$ & $36,3 \pm 12,1 \mathrm{Ab}$ & $42,1 \pm 19,2 \mathrm{Aa}$ & $53,6 \pm 42,1 \mathrm{Ab}$ \\
\hline 30 & $57,8 \pm 75,1 \mathrm{Ab}$ & $57,4 \pm 58,1 \mathrm{Ab}$ & $32,5 \pm 16,2 \mathrm{Ab}$ & $31,6 \pm 14,4 \mathrm{Aa}$ & $30,6 \pm 28,3 \mathrm{Ab}$ \\
\hline 60 & $24,8 \pm 10,4 \mathrm{Ab}$ & $28,7 \pm 14,0 \mathrm{Ab}$ & $24,6 \pm 8,02 \mathrm{Ab}$ & $22,0 \pm 4,90 \mathrm{Aa}$ & $23,0 \pm 7,08 \mathrm{Ab}$ \\
\hline 90 & $18,2 \pm 3,96 \mathrm{Ab}$ & $21,0 \pm 5,41 \mathrm{Ab}$ & $23,9 \pm 13,2 \mathrm{Ab}$ & $19,1 \pm 4,09 \mathrm{Aa}$ & $20,1 \pm 3,96 \mathrm{Ab}$ \\
\hline
\end{tabular}

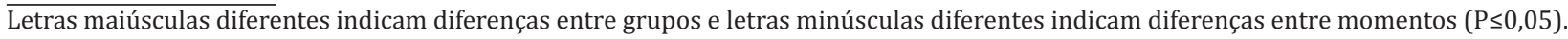

Quadro 3. Teores séricos de ceruloplasmina e transferrina de bezerros da raça Holandesa que receberam, por via IM, solução fisiológica estéril no 5\% dia de idade (grupo 1), $5 \mathrm{~mL}$ de ferro dextrano $10 \%$ no $5 \%$ dia de idade (grupo 2), no 5 e no $20^{\circ}$ dias de idade (grupo 3), no 5o e no $30^{\circ}$ dias de idade (grupo 4), no 5, no $20^{\circ}$ e no 45 dias de idade (grupo 5), logo após o nascimento (0) e com 5, 10, 20, 30, 60 e 90 dias de idade

\begin{tabular}{|c|c|c|c|c|c|}
\hline \multirow{2}{*}{$\begin{array}{c}\text { Momentos } \\
\text { (dias) }\end{array}$} & \multicolumn{5}{|c|}{ Grupos } \\
\hline & 1 & 2 & 3 & 4 & 5 \\
\hline \multicolumn{6}{|c|}{ Ceruloplasmina (mg/dL) } \\
\hline 0 & $29,2 \pm 11,7 \mathrm{Ab}$ & $20,7 \pm 19,6 \mathrm{Ab}$ & $28,5 \pm 19,2 \mathrm{Ab}$ & $42,0 \pm 16,3 \mathrm{Aa}$ & $44,7 \pm 33,0 \mathrm{Ab}$ \\
\hline 5 & $42,4 \pm 12,9 \mathrm{Aab}$ & $47,7 \pm 24,1 \mathrm{Aab}$ & $70,1 \pm 44,2 \mathrm{Aa}$ & $45,9 \pm 14,2 \mathrm{Aa}$ & $49,2 \pm 18,6$ Aab \\
\hline 10 & $41,4 \pm 11,9 \mathrm{Bab}$ & $52,6 \pm 24,8 \mathrm{ABab}$ & $90,3 \pm 48,5 \mathrm{Aa}$ & $61,0 \pm 30,1 \mathrm{ABa}$ & $65,0 \pm 21,1 \mathrm{ABab}$ \\
\hline 20 & $48,2 \pm 15,3 \mathrm{Bab}$ & $59,7 \pm 22,5 \mathrm{ABab}$ & $97,5 \pm 76,0 \mathrm{Aa}$ & $62,7 \pm 20,4 \mathrm{ABa}$ & $77,0 \pm 26,9 \mathrm{ABab}$ \\
\hline 30 & $53,8 \pm 21,1 \mathrm{Aab}$ & $52,7 \pm 42,3 \mathrm{Aab}$ & $91,3 \pm 44,8$ Aa & $65,7 \pm 17,0 \mathrm{Aa}$ & $87,5 \pm 22,2 \mathrm{Aa}$ \\
\hline 60 & $47,0 \pm 28,8 \mathrm{Aab}$ & $50,2 \pm 35,6 \mathrm{Aab}$ & $88,9 \pm 45,2 \mathrm{Aa}$ & $66,7 \pm 15,7 \mathrm{Aa}$ & $63,3 \pm 10,8 \mathrm{Aab}$ \\
\hline 90 & $80,8 \pm 52,5 \mathrm{Aa}$ & $62,6 \pm 48,8$ Aa & $65,5 \pm 31,6 \mathrm{Aab}$ & $57,0 \pm 39,4$ Aа & $63,7 \pm 25,4 \mathrm{Aab}$ \\
\hline \multicolumn{6}{|c|}{ Transferrina $(\mathrm{mg} / \mathrm{dL})$} \\
\hline 0 & $220 \pm 94,4 \mathrm{ABab}$ & $130 \pm 21,5 \mathrm{Ba}$ & $143 \pm 41,0 \mathrm{ABa}$ & $234 \pm 82,8 \mathrm{Aab}$ & $238 \pm 67,5 \mathrm{Aa}$ \\
\hline 5 & $259 \pm 96,5 \mathrm{Aa}$ & $185 \pm 53,8$ Aa & $206 \pm 61,0 \mathrm{Aa}$ & $287 \pm 94,2 \mathrm{Aa}$ & $236 \pm 83,6$ Aа \\
\hline 10 & $222 \pm 64,9 \mathrm{ABab}$ & $167 \pm 39,8 \mathrm{Ba}$ & $194 \pm 73,5 \mathrm{ABa}$ & $274 \pm 110$ Aа & $218 \pm 63,6 \mathrm{ABa}$ \\
\hline 20 & $179 \pm 32,9 \mathrm{Aab}$ & $203 \pm 80,0$ Aа & $170 \pm 40,2 \mathrm{Aa}$ & $248 \pm 70,3$ Aab & $223 \pm 56,3 \mathrm{Aa}$ \\
\hline 30 & $173 \pm 42,6 \mathrm{Aab}$ & $200 \pm 116 \mathrm{Aa}$ & $194 \pm 47,1 \mathrm{Aa}$ & $219 \pm 60,5$ Aab & $251 \pm 127 \mathrm{Aa}$ \\
\hline 60 & $170 \pm 68,8 \mathrm{Ab}$ & $193 \pm 74,0$ Аа & $200 \pm 78,8 \mathrm{Aa}$ & $263 \pm 67,7 \mathrm{Aab}$ & $215 \pm 53,9$ Аа \\
\hline 90 & $195 \pm 60,7 \mathrm{Aab}$ & $177 \pm 101 \mathrm{Aa}$ & $153 \pm 75,2 \mathrm{Aa}$ & $176 \pm 104 \mathrm{Ab}$ & $163 \pm 53,6 \mathrm{Aa}$ \\
\hline
\end{tabular}

Letras maiúsculas diferentes indicam diferenças entre grupos e letras minúsculas diferentes indicam diferenças entre momentos (P $\leq 0,05)$.

ou seja, não foi verificado aumento significativo das variáveis eritrocitárias, bem como do teor sérico de ferro, de maneira uniforme nos momentos subsequentes à administração da suplementação (Quadro 1 e Quadro 2). Com relação aos teores séricos de ferro, o único protocolo no qual verificou-se aumento desse parâmetro nos momentos subsequentes à administração foi o de aplicação de ferro dextrano no $5^{\circ}$ e no $20^{\circ}$ dias de vida (G3).

\section{DISCUSSÃO}

Em todos os grupos foi verificada diminuição na contagem de hemácias a partir do nascimento, que, entre o nascimento e os cinco dias de vida, pode ser explicada pela expansão do volume plasmático induzido pela ingestão de colostro e pela destruição de eritrócitos fetais (Rizzoli et al. 2006). No G1, a falta de suprimento adequado de ferro para a síntese de hemácias pode ser implicada como causa da diminuição na contagem desse tipo celular verificada entre o nascimento e os 60 dias de vida (Rizzoli et al. 2006). Segundo Jain (1993), a contagem de hemácias, o teor de hemoglobina e volume globular de bovinos, em geral, são mais elevados ao nascimento, com tendência à diminuição gradativa no decorrer de alguns meses até se estabilizarem. Apesar de não ter sido verificada diferença significativa entre grupos, a diminuição do número de hemácias constatada no G1 foi mais pronunciada do que nos demais grupos, fato considerado biologicamente importante. Isso indica que o ferro suplementar foi utilizado para produção destas células (Bunger et al. 1982). Todavia, as contagens de hemácias verificadas em todos os grupos encontraram-se dentro do intervalo de referência descrito para bezerros nesta faixa etária (Fagliari et al. 1998, Rocha et al. 
2010, Benesi et al. 2012), não sendo verificada a ocorrência de anemia em nenhum grupo.

Fagliari et al. (1998), Atyabi et al. (2006), Rizzoli et al. (2006) e Benesi et al. (2012) relataram diminuição significativa dos teores de hemoglobina em bezerros neonatos, o que não foi constatado no presente estudo, entretanto, existe a possibilidade de que a diminuição verificada nesse parâmetro possa apresentar importância biológica. Ježek et al. (2009) relataram os menores teores séricos de hemoglobina e de ferro na quinta semana de idade, o que corrobora os achados do presente estudo, no qual os menores teores de hemoglobina foram verificados aos 30 e 60 dias de idade, e os menores teores de ferro aos 60 dias de idade no grupo controle (G1) e aos 5 dias de idade no G3, G4 e G5, uma vez que no G2 não foi verificada diferença significativa entre momentos. Assim, a suplementação com ferro dextrano injetável mostrou-se importante, uma vez que possivelmente evitou uma diminuição significativa dos teores de ferro séricos a partir do 5ํ dia de vida. Entretanto, no G2 foi verificada diminuição dos teores séricos de ferro após a administração da suplementação com esse elemento aos 5 dias de vida; nesse caso, outros fatores não controlados no experimento, como manejo das vacas e reservas desse mineral no organismo dos bezerros podem ter interferido na resposta à suplementação. Notou-se que os grupos que receberam suplementação com ferro dextrano mantiveram teores maiores de hemoglobina, volume globular e teor sérico de ferro, embora em algumas ocasiões essa diferença não tenha sido significativa entre grupos. Considera-se que a ação biológica da suplementação realizada seja importante, uma vez que, no grupo controle, embora sem o desenvolvimento de anemia, a contagem de hemácias, teor de hemoglobina e volume globular foram menores que nos grupos suplementados. Diante da ocorrência de enfermidades comuns em bezerros jovens, tais como a tristeza parasitária bovina, diarreia e pneumonia, os animais do grupo controle apresentariam anemia mais precocemente que os animais suplementados, o que poderia ter influência significativa no desfecho dessas enfermidades nesses animais.

Os índices hematimétricos mantiveram-se no intervalo de referência para a espécie (Radostits et al. 2010, Jones \& Allison 2007) e não foi notada tendência ao decréscimo do VCM com o avançar da idade, como descrito por Mohri et al. (2007), Benesi et al. (2012) e Rocha et al. (2013). Segundo Reece et al. (1984) o tratamento com ferro suplementar induz aumento do VCM e CHCM, apesar de não ter sido notada diferença significativa entre grupos nestes dois parâmetros, verificou-se aumento discreto nos grupos que receberam suplementação com ferro.

Ademais, é importante ressaltar também que, apesar da introdução de ração e sal mineral na alimentação dos bezerros a partir dos 30 dias de idade, houve ainda um período de decréscimo, ainda que não significativo, nos parâmetros eritrocitários mesmo nos grupos que receberam a suplementação. Posteriormente, aos 90 dias de vida, tendo os bezerros sido desmamados, verificou-se então aumento nesses parâmetros, possivelmente decorrente da introdução de novas fontes de ferro na alimentação, uma vez que o leite não apresenta teores de ferro suficientes para suprir as necessidades dos bezerros na fase de crescimento (Atyabi et al. 2006).

A administração intramuscular de ferro dextrano não ocasionou aumento significativo nos teores séricos de ferro em nenhum dos grupos estudados, no entanto, as alterações verificadas podem apresentar importância biológica, uma vez que a avaliação do teor sérico de ferro reflete apenas o compartimento de transporte desse elemento, podendo os valores obtidos não apresentarem, necessariamente, o reflexo dos demais compartimentos de ferro no organismo (Kaneko et al. 2008). Ademais, constatou-se que a dose de ferro dextrano utilizada não ocasionou sobrecarga por esse elemento. Segundo Knowles et al. (2000), a concentração sérica de ferro em bezerros recém-nascidos diminui com a idade e só aumentam após 83 dias de vida. Tal afirmação foi semelhante ao descrito por Atyabi et al. (2006), que relataram que o teor sanguíneo de ferro diminui a partir de dois dias após o nascimento até, aproximadamente, dois meses de idade, influenciando a contagem de hemácias. Em estudo realizado por Fagliari et al. (1998), a diminuição do teor sérico de ferro, com o avanço da idade foi semelhante ao verificado para o teor de hemoglobina e para o volume globular. No presente estudo verificou-se diminuição mais acentuada da contagem de hemácias, teor de hemoglobina e volume globular aos 30 e 60 dias de idade e do teor sérico de ferro aos 60 dias de idade nos animais não suplementados com ferro (G1). Outros estudos com suplementação de ferro injetável mostraram aumento significativo nos parâmetros eritrocitários e no teor sérico de ferro (El-Sangary et al. 2004, Moosavian et al. 2010).

Os teores séricos de ureia, creatinina, bilirrubina total e direta encontram-se dentro dos valores de referência relatados para a espécie (Fagliari et al. 1998, Knowles et al. 2000). Já o fato da atividade sérica da enzima GGT mostrar-se maior ao nascimento do que nos demais momentos em todos os grupos é explicado pela alta atividade dessa enzima no colostro de vacas, sendo essa enzima absorvida pelos bezerros por ocasião da ingestão do colostro para garantia da transferência de imunidade passiva, e a diferença verificada entre os grupos neste momento deve-se às diferentes quantidade e qualidade do colostro ingerido por cada animal. Segundo Zanker et al. (2001), a atividade sérica alta de GGT em ruminantes neonatos é indicativa de ingestão adequada de colostro. Knowles et al. (2000) relatam que a atividade sérica desta enzima só chega ao valor normal de adultos por volta de 40 dias de idade.

Segundo Fagliari et al. (1998), a atividade de AST é maior ao nascimento e decresce com a idade; no presente estudo não foi constatada diferença entre grupos. Variações relativamente amplas foram notadas nos teores séricos da enzima ALP, com maiores valores logo após o nascimento, corroborando com os achados de Fagliari et al. (1998). Segundo Radostits et al. (2010), tais variações são comuns em bovinos normais, o que dificulta a interpretação de resultados da avaliação da atividade dessa enzima. Tais achados permitem afirmar que a aplicação intramuscular de ferro dextrano a 10\% em bezerros neonatos não ocasionou nefrotoxicidade nem hepatotoxidade.

Verificou-se que os teores séricos de ceruloplasmina foram significativamente menores ao nascimento, quando comparados aos demais momentos em todos os grupos, exceto o G4, sendo significativamente inferiores nos animais do G1 aos 10 e 20 dias de vida quando comparados aos demais grupos, corroborando o relato de Rocha et al. (2013). 
A ceruloplasmina é uma proteína de fase aguda envolvida no metabolismo de ferro, em especial na oxidação de $\mathrm{Fe}^{2+}$ a $\mathrm{Fe}^{3+}$, o que permite a incorporação do ferro à transferrina (Eckersall 2008, Tothova et al. 2014).

Segundo Tothova et al. (2014), o teor sérico de transferrina aumenta em bezerros com deficiência de ferro, resultando numa correlação negativa com os teores de hemolglobina, o que difere dos achados do presente estudo, no qual os teores séricos desta proteína de fase aguda tiveram comportamento semelhante aos encontrados para os teores séricos de ferro e para os parâmetros eritrocitários. Rocha et al. (2013), em estudo com animais da raça Canchim-Nelore, verificou teores menores dessa proteína ao nascimento, aumentando com o avançar da idade. A transferrina é uma proteína de fase aguda negativa envolvida no transporte de ferro, cujo valor diagnóstico está na avaliação de enfermidades que interferem no metabolismo deste elemento (Eckersall 2008, Tothova et al. 2014). Os valores obtidos no presente estudo foram semelhantes aos notados por Fagliari et al. (2007), em bezerros da raça Holandesa saudáveis, o que mostra que os animais do presente estudo não desenvolveram anemia no período avaliado.

Os teores séricos de creatinina, ureia e bilirrubinas total e direta e as atividades das enzimas AST, ALP e GGT foram normais para bezerros nesta faixa etária, sugerindo que os protocolos de administração de ferro suplementar não ocasionaram nefrotoxicidade ou hepatoxidade aos animais.

Uma vez que nenhum dos protocolos de suplementação com ferro dextrano injetável instituídos ocasionou aumento significativo dos parâmetros eritrocitários avaliados, bem como do teor sérico de ferro, não é possível recomendá-los como forma de suplementação visando evitar o desenvolvimento e anemia ferropriva em bezerros, já que em nenhum dos grupos avaliados, incluindo o grupo controle, foi constatado o desenvolvimento de anemia. Entretanto, foi possível estabelecer que, realizando até três aplicações utilizando a dose recomendada pelo fabricante, não foram constatados sinais de nefrotoxicidade nem de hepatotoxicidade.

\section{CONCLUSÃO}

A suplementação com ferro dextrano em bezerros que têm acesso a outras fontes de alimento que não apenas o leite não traz benefícios aos parâmetros eritrocitários e que justifiquem sua utilização, embora seja necessário realizar mais estudos para avaliar a influência da suplementação com ferro dextrano por via parenteral sobre a ocorrência e o desfecho de infecções em bezerros jovens, em especial quanto aos custos com o tratamento, tempo necessário para recuperação e impacto sobre a vida produtiva na idade adulta.

Agradecimentos.- Os autores agradecem à Fundação de Amparo à Pesquisa do Estado de São Paulo (FAPESP) pelo suporte financeiro e pelas bolsas de pesquisa concedidas.

\section{REFERÊNCIAS}

Atyabi N., Gharagozloo F. \& Nassiri S.M. 2006. The necessity of iron supplementation for normal development of commercially reared suckling calves. Comp. Clin. Pathol. 15(3):165-168. http://dx.doi.org/10.1007/ s00580-006-0624-4.
Barbosa J.C. \& Maldonado Júnior W. 2008. AgroEstat-Sistema para análises estatísticas de ensaios agronômicos, versão 1.0.

Benesi F.J., Teixeira C.M.C., Lisboa J.A.N., Leal M.L.R., Birgel Júnior E.H., Bohland E. \& Mirandola R.M.S. 2012. Eritrograma de bezerras sadias, da raça Holandesa, no primeiro mês de vida. Pesq. Vet. Bras. 32(4):357-360. http://dx.doi.org/10.1590/S0100-736X2012000400014.

Bergmeyer H.U. 1985. Methods of enzymatic analysis. Verlag Chemie, Deerfield Beach, p.444-449.

Birgel E.H. 1982. Hematologia clínica veterinária, p.2-34. In: Birgel E.H. \& Benesi F.J. (Eds), Patologia Clínica Veterinária. Sociedade Paulista de Medicina Veterinária, São Paulo.

Bowers Junior G.N. \& McComb R.B. 1975. Measurement of total alkaline phosphatase activity in human serum. Clin. Chem. 21(13):1988-1995. PMid:163.

Bünger U., Ponge J., Fiebig U., Kleiner W., Motsch T., Kaphengst P., Furcht G. \& Schmoldt P. 1982. Oral and intramuscular ferridextran intervention in growing male calves. 1. Hematologic reactions. Arch. Tierernähr. 32(56):349-368. PMid:7115076.

Burtis C.A., Ashwood E.R. \& Bruns D.E. 2007. Tietz Fundamentals of Clinical Chemistry. 6th ed. W.B. Saunders, Philadelphia. 976p.

Eckersall P.D. 2008. Proteins, proteomics, and the dysproteinemias, p.61176155. In: Kaneko J.J., Harvey J.W. \& Bruss M.L. (Eds), Clinical Biochemistry of Domestic Animals. Academic Press, San Diego.

El-Sangary F.H.M., Mohamed M.M. \& Faris A.E.S. 2004. Efficacy of iron dextran in prevention of nutritional anaemia in newly-born cattle calves. 1st Annual Conference FVM, Moshtohor.

Fagliari J.J., Santana A.E., Lucas F.A., Campos Filho E. \& Curi P.R. 1998. Constituintes sangüíneos de bovinos recém-nascidos das raças Nelore e Holandesa e de bubalinos da raça Murrah. Arq. Bras. Med. Vet. Zootec. 50:253-262.

Fagliari J.J., Passipieri M., Okuda H.T., Silva S.L. \& Silva P.C. 2007. Serum protein concentrations, including acute phase proteins, in calves with hepatogenous photosensitization. Arq. Bras. Med. Vet. Zootec. 59(6):1355-1358. http:// dx.doi.org/10.1590/S0102-09352007000600001.

Goodwin J.F., Murphy B. \& Guillemette M. 1966. Direct measurement of serum iron and binding capacity. Clin. Chem. 12(2):47-57. PMid:4952421.

Gygax M., Hirni H., Zwahlen R., Lazary S. \& Blum J.W. 1993. Immune functions of veal calves fed low amounts of iron. Zentralbl. Veterinärmed. A 40(5):345-358. PMid:8212950. http://dx.doi.org/10.1111/j.1439-0442.1993.tb00638.x.

Heidarpour Bami M., Mohri M., Seifi H.A. \& Alavi Tabatabaee A.A. 2008. Effects of parenteral supply of iron and copper on hematology, weight gain, and health in neonatal dairy calves. Vet. Res. Commun. 32(7):553561. PMid:18478351. http://dx.doi.org/10.1007/s11259-008-9058-6.

Henry R.J., Chiamori N., Golub 0.J. \& Berkman S. 1960. Revised spectrophotometric methods for the determination of glutamic-oxalacetic transaminase, glutamic-pyruvic transaminase, and lactic acid dehydrogenase. Am. J. Clin. Pathol. 34:381-391. PMid:13713438.

Jain N.C. 1993. Essentials of Veterinary Hematology. Lea and Febiger, Philadelphia. $417 p$.

Ježek J., Starič J., Nemec M., Tomaž Z. \& Klinkon M. 2009. Relationship between blood haemoglobin and serum iron concentrations and heart girth in pre-weaned dairy calves. It. J. Anim. Sci. 8(sup3):151-153. http://dx.doi. org/10.4081/ijas.2009.s3.151.

Jones M.L. \& Allison R.W. 2007. Evaluation of the ruminant complete blood cell count. Vet. Clin. North Am. Food Anim. 23(3):377-402. http://dx.doi. org/10.1016/j.cvfa.2007.07.002.

Kaneko J.J., Harvey J.W. \& Bruss M.L. 2008. Clinical Biochemistry of Domestic Animals. 904 p. 
Knowles T.G., Edwards J.E., Bazeley K.J., Brown S.N., Butterworth A. \& Warriss P.D. 2000. Changes in the blood biochemical and hematological profile of neonatal calves with age. Vet. Rec. 147(21):593-598. PMid:11110479. http://dx.doi.org/10.1136/vr.147.21.593.

Laemmli U.K. 1970. Cleavage of structural proteins during the assembly of the head of bacteriophage T4. Nature 227(5259):680-685. PMid:5432063. http://dx.doi.org/10.1038/227680a0.

Moosavian H.R., Mohri M. \& Seifi A. 2010. Effects of parenteral over-supplementation of vitamin A and iron on hematology, iron biochemistry, weight gain, and health of neonatal dairy calves. Food Chem. Toxicol. 48(5):1316-1320. PMid:20188781. http://dx.doi.org/10.1016/j.fct.2010.02.030.

Mohri M., Sarrafzadeh F., Seifi H.A. \& Farzaneh N. 2004. Effects of oral iron supplementation on some haematological parameters and iron biochemistry in neonatal dairy calves. Comp. Clin. Pathol. 13(2):39-42. http://dx.doi. org/10.1007/s00580-004-0523-5.

Mohri M., Sharifi K. \& Eidi S. 2007. Hematology and serum biochemistry of Holstein dairy calves: Age related changes and comparison with blood composition in adults. Res. Vet. Sci. 83(1):30-39. PMid:17188315. http:// dx.doi.org/10.1016/j.rvsc.2006.10.017.

National Research Council 2001. Nutrient requirements of dairy cattle. Natl Acad. Sci, Washington, DC.

Radostits O.M., Gay G.C., Hinchcliff K.W. \& Constable P.D. 2010. Veterinary Medicine: a textbook of the diseases of cattle, horses, sheep, pigs, and goats, p.357-374.

Ramin A.G., Asri-Rezaei S., Paya K., Eftekhari Z., Jelodary M., Akbari H. \& Ramin S. 2012. Evaluation of anemia in calves up to 4 months of age in Holstein dairy herds. Vetscan 7:87-92.

Reece W.O., Self H.L. \& Hotchkiss D.K. 1984. Injection of iron in newborn beef calves: erythrocyte variables and weight gains with newborn-dam correlations. Am. J. Vet. Res. 45(10):2119-2122. PMid:6497111.

Rizzoli F.W., Fagliari J.J. \& Silva D.G. 2006. Teores séricos de cálcio, fósforo, magnésio e ferro de bezerros recém-nascidos que mamaram colostro diretamente na vaca ou em mamadeira. Ars Vet. 22:4-8.
Rocha T.G., Franciosi C., Nociti R.P., Nogueira C.A.S. \& Fagliari J.J. 2010. Hemograma e proteínas do soro sanguíneo de bezerros Canchim-Nelore e da raça Holandesa nos primeiros 30 dias de vida. Arq. Bras. Med. Vet. Zootec. 62(5):1250-1254. http://dx.doi.org/10.1590/S0102-09352010000500030.

Rocha T.G., Nociti R.P., Sampaio A.A.M. \& Fagliari J.J. 2013. Hemograma e proteínas de fase aguda de bezerros sadios do nascimento aos 30 dias de idade. Pesq. Vet. Bras. 33(supl. 1):25-31. http://dx.doi.org/10.1590/ S0100-736X2013001300005.

Schumann G., Bonora R., Ceriotti F., Férard G., Ferrero C.A., Franck P.F., Gella F.J., Hoelzel W., Jørgensen P.J., Kanno T., Kessner A., Klauke R., Kristiansen N., Lessinger J.M., Linsinger T.P., Misaki H., Panteghini M., Pauwels J., Schiele F., Schimmel H.G., Weidemann G. \& Siekmann L., and the International Federation of Clinical Chemistry and Laboratory Medicine. 2002. IFCC primary reference procedures for the measurement of catalytic activity concentrations of enzymes at 37 degrees C. International Federation of Clinical Chemistry and Laboratory Medicine. Part 6. Reference procedure for the measurement of catalytic concentration of gamma-glutamyltransferase. Clinical chemistry and laboratory medicine 40(7):734-738. PMid:12241023.

Sims F.H. \& Horn C. 1958. Some observations on Powell's method for the determination of serum bilirubin. Am. J. Clin. Pathol. 29(5):412-417. PMid:13533339. http://dx.doi.org/10.1093/ajcp/29.5.412.

Thrall M.A. 2007. Hematologia e Bioquímica Clínica Veterinária. Roca, São Paulo. 582p.

Tothova C., Nagy O. \& Kovac G. 2014. Acute phase proteins and their use in the diagnosis of diseases in ruminants: a review. Veterinarni Medicina 59:163-180.

Zanker I.A., Hammon H.M. \& Blum J.W. 2001. Activities of $\gamma$-glutamyltransferase, alkaline phosphatase and aspartate-aminotransferase in colostrum, milk and blood plasma of calves fed first colostrum at $0 \pm 2,6 \pm 7,12 \pm 13$ and 24 \pm 25 h after birth. J. Vet. Med. A. Physiol. Pathol. Clin. Med. 48(3):179-185. PMid:11379391.http://dx.doi.org/10.1046/j.1439-0442.2001.00338.x. 